\title{
Programa de Saúde da Família e qualidade de vida: um olhar da Psicologia
}

\author{
Rafaela Assis de Souza \\ Alysson Massote Carvalho \\ Universidade Federal de Minas Gerais
}

\begin{abstract}
Resumo
Referenciado no atual modelo de reorganização do sistema de saúde pública do Brasil, esse trabalho objetiva demonstrar alguns dos impactos da proposta do Programa de Saúde da Família (PSF) na qualidade de vida e na saúde da população. Sob o ponto de vista da observação participante, são descritas as atividades promovidas pelo PSF de um município de Minas Gerais, a partir das quais observou-se que a participação popular, a multidimensionalidade das ações, o incentivo à autonomia e a contextualização e humanização do atendimento possibilitaram melhorias nas condições de vida da comunidade alvo. Verificou-se a congruência entre tais intervenções e os princípios orientadores da atenção básica desse novo modelo de saúde, destacando-se também elementos que contribuem para a promoção da saúde e a elevação dos níveis de qualidade de vida dessa comunidade. A partir do relato dessa experiência é apresentada uma proposta de inserção do profissional de psicologia no PSF.

Palavras-chave: qualidade de vida; programa de saúde da família; psicologia da saúde
\end{abstract}

\begin{abstract}
Health Care Family Program and quality of life: a view from Psychology. In reference to the current reorganization of the public health care system of Brazil, this paper aimed to demonstrate some impacts of the proposed Health Care Family Program (HCFP) on quality of life and health of the general population. Activities promoted by the HCFP in a municipality of the state of Minas Gerais are described. Employing participant observation, it was observed that the engagement of local people, the multidimensionality of the actions, the incentive towards autonomy and a contextual and more humane aid have altogether made it possible to improve the living conditions of the target community. The congruence between such interventions and the directional principles of the new Health Care Program primary focus has been verified, as well as other contributing elements of health promotion and improvement of the quality of life of the community. Based on such report a proposal for the insertion of practitioners of psychology in the Health Care Family Program is presented.
\end{abstract}

Key words: quality of life; health care family program; health psychology

$\mathrm{O}$ Ministério da Saúde assume, desde a Constituição de 1988, o compromisso de reestruturar o modelo de atenção no Brasil partindo de um referencial de saúde como direito de cidadania, pressupondo a organização de serviços cada vez mais resolutivos, integrais e humanizados. Nessa proposta, o poder público municipal fica investido da responsabilidade imediata de atendimento das necessidades e demandas de saúde de todos os seus munícipes, contando com a devida cooperação técnica e financeira da União e dos estados, de acordo com o previsto na Norma Operacional Básica do Sistema Único de
Saúde (Brasil, 1996). Essa estratégia de descentralização objetiva facilitar o acesso dos indivíduos e possibilitar uma gerência de saúde mais adequada ao contexto da população atendida, oferecendo serviços de melhor qualidade. No âmbito dessas mudanças, várias políticas municipais têm se organizado a partir do Programa de Saúde da Família (PSF), proposta que se insere no nível da atenção básica e que persegue o objetivo final de promover a qualidade de vida e o bem estar individual e coletivo por meio de ações e serviços de promoção, proteção e recuperação da saúde. 
Tendo como referência a atuação de duas equipes de saúde do PSF em um município do interior do estado de Minas Gerais, o presente trabalho apresenta algumas das ações referenciadas nesse novo modelo de assistência à saúde e reflete acerca da implicação dessas na promoção da qualidade de vida da população atendida. É feita uma reflexão a respeito de como as estratégias de prevenção e promoção da saúde propostas pelo PSF estariam voltadas não apenas para a atenção pontual, mas também para as condições de vida das populações, tendo em vista a amplitude do conceito de saúde admitido atualmente.

De maneira geral, abordar os efeitos advindos de uma nova proposta de intervenção nas condições de vida das populações, tais como mudanças no modelo de assistência, oferta de novos serviços, incentivo à participação e organização comunitária, entre outros efeitos, adquire grande relevância, visto que as transformações estruturais, conceituais e práticas conseqüentes envolvem condições primárias de sobrevivência, como é o caso da assistência básica à saúde. Qualquer aspecto relativo à saúde, por sua importância inerente ao ser humano, tem, portanto, relevância social. Para o município em questão, avaliar o compromisso desse modelo de atenção na promoção da qualidade de vida da população se faz necessário, diante dos impactos da reestruturação dos serviços e das ações de saúde promovidas pelo PSF na comunidade. Particularmente, esse município tem sido palco de várias mudanças tanto na organização de seu modelo de saúde coletiva quanto nas condições de vida de sua população, de modo geral. Analisar as ações baseadas no novo modelo brasileiro de organização da atenção à saúde pública é válido, ainda, ao subsidiar com dados baseados em experiências significativas que possam favorecer o aperfeiçoamento dessa estratégia, cujos efeitos estarão sendo sentidos em toda a população brasileira. O presente estudo pretende contribuir também para a indicação de novas propostas de intervenção, visando integrá-las às demandas da comunidade.

Serão descritas as atividades com os grupos programáticos de hipertensos, diabéticos, gestantes e do Sistema de Vigilância Nutricional (SISVAN), grupo da terceira idade, grupo de jovens, Projeto de Educação em Saúde, atendimentos psicológicos à população em geral (triagem psicológica, plantão psicológico, psicoterapia breve de grupo), e planejamento estratégico com as equipes do PSF. O estudo é baseado na observação e/ou participação de estagiárias do Internato Rural ${ }^{1}$ de psicologia da UFMG nessas atividades, a partir das quais são discutidos seus impactos na qualidade de vida da população atendida.

Considerando assim os objetivos desse trabalho, é importante abordar, a princípio, os conceitos de qualidade de vida e saúde, além de apresentar a proposta de trabalho do PSF estabelecida pelo Ministério da Saúde.

\section{Qualidade de vida: conceitos}

Desde os anos sessenta do século passado, a expressão qualidade de vida tem sido referência de inúmeros discursos acadêmicos, políticos, ideológicos e outros, movidos principalmente pelo interesse das Nações Unidas, ainda na década de 50, de mensurar os níveis de vida de diversas comunidades mundiais. Ainda hoje esse conceito tem uma definição imprecisa, não existindo um consenso teórico a seu respeito. Uma boa parte dessas investigações, inicialmente, associava a qualidade de vida a um conceito quantitativo, relativo a recursos materiais disponíveis para determinado indivíduo ou sociedade (Corrêa, 2001). Observa-se, entretanto, que os esforços atuais em defini-lo tendem para uma abordagem mais ampla e integradora.

Nesse sentido, a Organização Mundial da Saúde, propondo uma natureza multifatorial da qualidade de vida, refere-se a esse conceito a partir de cinco dimensões: (1) saúde física, (2) saúde psicológica, (3) nível de independência (em aspectos de mobilidade, atividades diárias, dependência de medicamentos e cuidados médicos e capacidade laboral), (4) relações sociais e (5) meio ambiente. Trata-se de visão global, que considera as várias dimensões do ser humano na determinação dos níveis de qualidade de vida de cada indivíduo. Wilheim (1978) já agregava a esse conceito a mesma visão, entendendo-o como a "sensação de bem estar dos indivíduos” (p. 133), relativo a fatores objetivos e subjetivos da experiência humana.

A complexidade em se quantificar os fatores subjetivos não pode, portanto, excluí-los das considerações acerca da qualidade de vida. Mesmo que critérios materiais específicos da experiência cotidiana sejam usados como indicadores, a dimensão subjetiva deve ser observada a fim de que se tenha uma percepção integral desse conceito. Dessa forma, Rueda (1997) considera a qualidade de vida como uma condição complexa e multifatorial sobre a qual é possível desenvolver algumas formas de medidas objetivas, através de uma série de indicadores, porém a vivência que o sujeito - ou grupo social - pode ter de si mesmo, tem um importante peso específico.

Assim, a qualidade de vida não pode ser tomada como um conceito geral, mas entendida dentro da experiência cotidiana e pessoal de cada um dos envolvidos. Prover ótimas condições de sobrevivência não garante a elevação dos níveis de qualidade de vida, visto que o que determina é a forma e a capacidade do indivíduo em perceber e se apropriar dessas condições. De nada adiantam os recursos se o beneficiário não pode se favorecer deles. Além disso, viver com qualidade é uma condição que satisfaz as exigências e demandas que determinada situação inflige aos indivíduos, dentro de um dado contexto particular. Qualquer fenômeno social deve ser considerado no âmbito de seu contexto histórico e entendido dentro da conjuntura política, econômica e cultural na qual se processa, inclusive a condição de qualidade de vida (Sliwiany, 1997).

A teoria dos Sistemas Ecológicos de Bronfenbrenner (1979/1996), que afirma a complexidade da natureza humana sob a perspectiva do desenvolvimento, fundamenta os modelos que consideram o caráter biopsicossocial do indivíduo. Nesse sentido, o desenvolvimento se dá dentro de dimensões biopsicossociais nas quais cada sujeito se encontra. À luz da complexidade de sistemas ecológicos nos 
quais o indivíduo se desenvolve, adotam-se referências de qualidade de vida que operem sob esses múltiplos fatores. Um outro modelo de seleção de indicadores de qualidade de vida que parte desse enfoque multifatorial é apresentado por Allardt (1973). Esse autor propõe que os valores relacionados ao conceito de bem-estar devam ser compreendidos a partir de três categorias básicas de valores. A primeira categoria (having) diz respeito aos recursos individuais de satisfação das necessidades primárias de vida e segurança. A segunda categoria (loving) compreende valores afiliativos, sociais e interpessoais, enquanto que a terceira categoria (being) se refere à satisfação das necessidades de desenvolvimento do self, agregando a singularidade do sujeito como ser único no mundo. Enquanto a categoria having compreende dados sócio-demográficos dos indicadores sociais, as categorias loving e being são de caráter psicológico e social. Allardt admite que seu modelo tridimensional guarda certa correspondência com a teoria da hierarquia de necessidades de Maslow, cujos sistemas de necessidades podem ser tomados também como parâmetros de promoção da qualidade de vida. Uma vez satisfeitas as necessidades relacionadas à simples sobrevivência (fisiológicas), outros grupos de necessidades dominariam o indivíduo hierarquicamente (segurança, amor, estima e auto-realização), fazendo-o avançar em suas condições de bem-estar. Assim, sustenta-se que a qualidade de vida se eleva através de uma escala de valores que avança desde a satisfação das necessidades básicas do ser humano em direção ao sentimento de bem-estar subjetivo e social.

Baseados nesses referenciais teóricos, se considera para esse estudo, o conceito de qualidade de vida como a condição biopsicossocial de bem estar, relativa a experiências humanas objetivas e subjetivas e considerada dentro das particularidades individuais e sociais da situação singular. Refere-se, portanto, a uma definição de caráter contextual, devendo ser entendida dentro das especificidades de cada situação, e multidimensional, considerando os vários determinantes da condição humana.

\section{Qualidade de vida e promoção da saúde}

Intervenções que visam a elevação da qualidade de vida são palco para que diversos atores sociais atuem na promoção do bem-estar humano e na organização de uma sociedade cada vez melhor, considerando o caráter multidimensional desse conceito. Uma proposta que se implica na elevação da qualidade de vida deve envolver-se de políticas intersetoriais que incentivem e proporcionem condições de bem-estar e desenvolvimento individual e coletivo. Nesse contexto, as ações dirigidas à saúde, em particular, adquirem grande relevância.

Uma boa saúde é o melhor recurso para o progresso pessoal, econômico e social, e uma dimensão importante da qualidade de vida. Os fatores políticos, econômicos, sociais, culturais, de meio ambiente, de conduta e biológicos podem intervir a favor ou contra a saúde. O objetivo da ação pela saúde é fazer com que essas condições sejam favoráveis para se poder promover a saúde (Conferência Internacional sobre a Promoção da Saúde, 1986).
As propostas de promoção da saúde, apresentadas pela primeira vez na Primeira Conferência Internacional sobre Promoção da Saúde, realizada em Ottawa, 1986, entendem a saúde como elemento importante no conjunto de condições indispensáveis à qualidade de vida. Entendida como um estado de completo bem-estar físico, mental e social, esse conceito de saúde supera o caráter estático, exclusivamente sanitário e de ausência de enfermidade, característicos do conceito anteriormente adotado, o qual não abarcava a amplitude de aspectos que a saúde representa. As estratégias de promoção da saúde voltam-se para estilos de vida e condições sociais, econômicas e ambientais que determinam a saúde e, de forma mais ampla, a qualidade de vida. Dessa forma, as ações em prol da saúde demandam a participação dos diversos setores da sociedade, não podendo ser asseguradas apenas pelo setor sanitário.

O Brasil, a partir da Constituição de 1988, assume o compromisso de reorganizar seu modelo de atenção à saúde, referenciado na perspectiva de saúde como direito de cidadania e como recurso que apóia o desenvolvimento individual e coletivo, agregando práticas assistenciais, preventivas e educativas. Tem como princípios norteadores garantir o acesso universal, equânime e o atendimento integral e descentralizado da saúde. Nessa proposta, estão compreendidos os campos da assistência, das intervenções ambientais e das políticas externas ao setor de saúde que interferem nos determinantes sociais do processo saúdedoença das coletividades. Os níveis de atenção à saúde são representados pela promoção, proteção e recuperação da saúde, nos quais deve ser sempre priorizado o caráter preventivo. Trata-se de um modelo de atenção centrado na qualidade de vida e na relação das equipes de saúde com a comunidade, privilegiando a abordagem familiar (Brasil, 1996). A reorganização do sistema de saúde brasileiro, de acordo com esse novo referencial, tem dado origem a várias estratégias e programas de intervenção, entre eles o Programa de Saúde da Família (PSF). Baseadas no princípio de saúde como direito de todos, o objetivo dessas propostas é garantir a promoção da saúde através de um atendimento acessível a todos, de forma contínua, integral e de qualidade.

\section{Programa de Saúde da Família}

Incorporando e ampliando o Programa de Agentes Comunitários de Saúde (PACS), as primeiras equipes do Programa de Saúde da Família foram formadas em janeiro de 1994. Priorizando ações de proteção e promoção da saúde, o atendimento é prestado na unidade básica de saúde ou no domicílio, por uma equipe multiprofissional composta por médico, enfermeiro, auxiliar de enfermagem e agentes comunitários de saúde. Cada equipe é levada a conhecer a realidade das famílias pelas quais é responsável, por meio de cadastramento e diagnóstico de suas características, tornando-se mais sensível às necessidades dos indivíduos atendidos. Recomenda-se que uma equipe seja responsável por, no máximo, 4.500 pessoas. Assim esses profissionais e a população acompanhada criam vínculos de coresponsabilidade, o que facilita a identificação e o atendimento 
aos problemas de saúde da comunidade mais facilmente. A reorganização da atenção básica pressupõe ainda o funcionamento de um sistema de referência e contra-referência eficiente que assegure a integralidade das ações de saúde.

No estado de Minas Gerais, existem atualmente 1586 equipes de PSF. Com o objetivo de colaborar para o desenvolvimento dos serviços básicos e do PSF nesse estado, as equipes são apoiadas pelo Pólo de Capacitação, Formação e Educação Permanente de Pessoal para Saúde da Família, estabelecido por meio de um convênio entre o Ministério da Saúde e a Universidade Federal de Minas Gerais desde 1998.

\section{Método}

Considerando o objetivo de apresentar algumas das estratégias de atuação do PSF em um município, referenciadas na proposta de reorganização da assistência à saúde do Brasil, optou-se pelo modelo de investigação tipo estudo exploratório de caráter descritivo (Selltiz, Jahoda, Deutsch, \& Cook, 1965), o qual permitiria a compreensão de uma dada realidade a partir de descrições acerca de suas características e do posterior levantamento de hipóteses referentes a essa experiência. Estagiários de psicologia do Internato Rural da UFMG, inseridos na dinâmica do município, tiveram a oportunidade de observar e/ou participar das ações promovidas pelo programa e, a partir daí, analisá-las à luz do conceito de qualidade de vida descrito anteriormente.

\section{Participantes}

Habitantes do município integrantes dos grupos observados (grupos programáticos de hipertensos, diabéticos, gestantes e do Sistema de Vigilância Nutricional/ SISVAN, grupo da terceira idade e grupo de jovens), professores de uma escola municipal e pacientes atendidos pelo serviço de psicologia, bem como os profissionais de saúde das equipes do PSF estiveram de alguma maneira envolvidos com essa experiência, num total aproximado de 200 pessoas.

\section{Instrumentos}

Roteiros de observação para registro cursivo das atividades promovidas pelo PSF e dos atendimentos psicológicos realizados pelas estagiárias de psicologia, além de relatórios de registro das atividades promovidas pelas equipes de saúde, das quais os responsáveis pela presente pesquisa não participaram diretamente, foram utilizados como instrumentos de coleta dos dados desse trabalho.

\section{Procedimentos}

Os dados referentes a esse relato de experiência foram coletados durante o estágio no Internato Rural de Psicologia no referido município, por duas acadêmicas da UFMG, a partir dos relatórios de observação registrados pelas próprias estagiárias. Para as atividades dos Grupos Programáticos, nas quais as acadêmicas não estiveram presentes, os dados foram extraídos dos relatórios feitos pelos profissionais das equipes de saúde que promoveram tais atividades. Na Tabela 1 encontram-se relacionados o número de reuniões ou atendimentos realizados em cada atividade analisada.

\section{Caracterização do município}

O município localiza-se a $320 \mathrm{Km}$ de distância de Belo Horizonte, na região do Alto São Francisco, estado de Minas Gerais. Possui uma população total de 7606 habitantes (Instituto Brasileiro de Geografia e Estatística, 1997) e densidade demográfica de 3,64 hab./ $\mathrm{km}^{2}$, tendo $71 \%$ de sua população residente na área urbana. A agricultura, a pecuária e o comércio são as principais atividades econômicas da região (26\% da área do município foi antropisada pela agricultura). Às margens de uma represa, o município apresenta um potencial turístico natural significativo, tendo o turismo como fonte de geração de emprego e renda para o município.

Em termos da organização da assistência à saúde, o município já encontra-se em Gestão Plena de Atenção Básica, na qual se organiza a estratégia do PSF, mas ainda não está habilitado como gestor pleno de saúde. A cidade possui um hospital, sendo 20 o número de leitos, oito unidades ambulatoriais e um consultório odontológico. O PSF conta com duas equipes de saúde que oferecem atendimento a todo

Tabela 1

Reuniões ou atendimentos de que cada grupo de sujeitos participou em cada atividade

\begin{tabular}{cc}
\hline Atividades & $\begin{array}{c}\text { Reuniões ou } \\
\text { atendimentos }\end{array}$ \\
\hline
\end{tabular}

1. Grupos programáticos

a) Hipertensos 40

b) Diabéticos 20

c) Gestantes 22

d) SISVAN ${ }^{\text {a }} 22$

2. Grupo da terceira idade 18

3. Grupo de jovens 6

4. Projeto de educação em saúde 11

5. Atendimentos psicológicos ${ }^{\mathrm{b}} \quad 110$

6. Planejamento estratégico 20

\footnotetext{
${ }^{a}$ Os atendimentos psicológicos foram realizados no hospital municipal, pelas estagiárias de Psicologia do Internato Rural da UFMG

${ }^{\mathrm{b}}$ Sistema de Vigilância Nutricional
} 
o município, incluindo a zona rural. Além dos profissionais de saúde, estudantes de medicina e de psicologia vinculados ao Internato Rural da UFMG atuam também junto ao PSF do município.

\section{Relato da experiência}

\section{O PSF no município}

Como preconizam os fundamentos básicos de implantação do PSF, realizou-se inicialmente um inquérito domiciliar para que as famílias fossem cadastradas e o município organizado em microrregiões. Com esse inquérito, foi possível obter-se um diagnóstico socioeconômico e epidemiológico do município, que orientou o planejamento das ações e permitiu o acompanhamento das pessoas cadastradas. Junto a essa coleta de dados, outras formas de conhecimento do contexto do município foram utilizadas para que subsidiassem a definição das estratégias que seriam implementadas, tais como dados secundários, vivências e diálogos com os vários setores sociais, população, profissionais e gestores dos municípios. Esse tipo de metodologia tinha a finalidade de delimitar um quadro mais realístico da situação da saúde da população e viabilizar a inserção dos profissionais de saúde na dinâmica própria da comunidade, durante a coleta de dados. Sendo a família o núcleo básico de ação do PSF, as visitas domiciliares realizadas pelas equipes de saúde, além de expandir o conhecimento acerca das condições de vida da população adscrita, possibilitaram a oferta de uma assistência mais contínua e presente. Essa aproximação cria vínculos entre comunidade e profissionais de saúde, elevando a aceitação do programa pelas pessoas. Como conseqüência da prestação de serviços mais integrais e humanizados, em conformidade com a Constituição Federal em vigor que prevê a criação de "condições de viabilização plena do direito à saúde", o PSF se baseia na elevação do nível de satisfação do usuário como indicador da qualidade de sua assistência. Assim a prática das visitas tende a resgatar o fator humano que se perdeu ao longo de um sistema meramente assistencial. Essa relação tem incentivado os sujeitos a se implicarem pessoalmente nesse processo, à medida que valoriza suas formas particulares de viver com qualidade e os responsabiliza na realização de seu próprio bem-estar.

Um aspecto particular desse município é a presença de acadêmicos de psicologia nas equipes de PSF. Nessa perspectiva, a psicologia tem participado de um trabalho integrado às equipes de saúde incorporando ações educativas, psicossociais e de planejamento organizacional. O objetivo é se envolver com as práticas de saúde no sentido de torná-las cada vez mais humanizadas e integrais, como o previsto pela atual legislação da saúde pública. Contando com o apoio da psicologia, por meio desses estagiários, o projeto do PSF utiliza-se do conhecimento adquirido ao longo de seu contato junto à população para definir estratégias e estruturar atividades que atendam efetivamente às necessidades do município.
Considerando os objetivos propostos para esse estudo, segue a descrição e análise das atividades especificadas na Tabela 1, tendo como referencial orientador esse processo de desenvolvimento das ações do PSF no município investigado.

\section{Grupos programáticos}

O trabalho com grupos programáticos ou temáticos tem se configurado como uma das principais atividades do PSF. No município investigado, quatro tipos de pacientes já foram organizados: hipertensos, diabéticos, gestantes e crianças do SISVAN. Nesses grupos, os pacientes são assistidos regularmente pelas equipes de saúde durante reuniões periódicas. Além do monitoramento da saúde, tais reuniões permitem a divulgação de informações a respeito do tema em questão, o que contribui para a educação do paciente (ou dos responsáveis por ele, no caso das crianças do SISVAN) em relação aos cuidados com a saúde e ao sucesso dos tratamentos.

Nessas atividades, a psicologia trabalhou no sentido de dar um suporte metodológico das reuniões às equipes do PSF. Essa proposta interdisciplinar se dispôs a promover intervenções educativas e de sensibilização mais eficazes, através de uma abordagem dinâmica e participativa, possibilitando um maior alcance da população e favorecendo a implicação dos participantes nas atividades promovidas. $\mathrm{O}$ trabalho de mediação por parte da psicologia teve a preocupação de difundir a informação de maneira acessível e contextualizada, levando em conta as capacidades e peculiaridades do público ao qual se dirigiam.

Supondo que o sujeito é o único capaz de promover sua transformação e aperfeiçoamento pessoal, as intervenções junto aos grupos programáticos se nortearam pelo incentivo à autonomia e responsabilização do paciente pelo seu próprio estado de saúde. Acredita-se que na medida em que o sujeito toma para si o poder de controlar sua própria vida, ele adquire a possibilidade de se desenvolver em uma direção congruente às suas potencialidades pessoais, respondendo as demandas externas de acordo com suas possibilidades individuais (Rudio, 1998). A responsabilidade do sujeito sobre os meios de padecimento e de controle de sua doença constitui-se como um dos pilares da promoção de saúde citado na Carta de Ottawa (Conferência Internacional sobre a Promoção da Saúde, 1986), através da qual ele se torna capaz de modificar esses meios em favor de sua saúde e do seu próprio bemestar.

Ao longo do monitoramento dos pacientes diabéticos e hipertensos, por exemplo, as equipes do PSF constataram uma melhora nos índices de saúde de grande parte deles, observando-se uma queda nos índices de pressão arterial e de glicemia. Em se tratando de patologias como hipertensão e diabetes, essa melhora é atribuída à associação do tratamento medicamentoso com a prática de exercícios físicos e uma dieta adequada. Nesse sentido, a mudança de atitudes do paciente em favor do controle de sua doença é essencial para o sucesso do tratamento. Apesar de incentivada pelas práticas educativas, a efetivação dessas mudanças só depende da 
tomada de consciência do paciente, que se implica pessoalmente em seu processo de promoção da saúde.

Com os grupos de gestantes, a atenção dada a essa população tem demonstrado efeitos a longo prazo, quando se observam mães mais instruídas e conscientes, beneficiando o desenvolvimento de crianças bem assistidas e saudáveis. Percebeu-se o quanto as ações educativas se refletem positivamente no nível preventivo, tão enfatizado pelas políticas de promoção da saúde. Por outro lado, nos grupos do Sistema de Vigilância Nutricional (SISVAN), programa de assistência a crianças desnutridas de 0 a 05 anos, observouse que as intervenções não haviam sido totalmente assimiladas pelas mães das crianças, sendo mínimo o comprometimento destas com as propostas da equipe do PSF. Não foram percebidas melhoras significativas no estado de saúde das crianças e o grupo de mães atendidas pelo programa não se mostrou comprometido em reverter a situação de baixo peso dos filhos, a fim de que a família não fosse desligada do programa e deixasse de receber a cota de leite em pó a que tinham direito. Acredita-se que a desnutrição infantil é apenas um sintoma e o SISVAN uma medida paliativa dentro de uma realidade caracterizada por um baixo nível socioeconômico, carente de intervenções em várias dimensões. O trabalho do PSF que tem como referencial norteador a elevação da qualidade de vida de sua população não pode ficar restrito a medidas que atenuem um problema cuja amplitude foge à sua capacidade de atuação. Tais medidas precisam ser substituídas por estratégias que visem a melhoria das condições de vida dessas famílias por meio de ações intersetoriais que atuem também nos níveis da geração de renda, alimentação, educação, habitação e saneamento, oferecendo condições mínimas para uma existência digna e para a prevenção de situações de risco.

Em relação às atividades com os grupos programáticos, de maneira geral, além do caráter educativo e de monitoramento dos pacientes, firmam-se espaços de apoio e compartilhamento de vivências comuns, permitindo mudanças também nas esferas sociais e psicológicas do indivíduo. Acredita-se que a abordagem em grupo promove um espaço sócio-pedagógico de incentivo a uma vida de qualidade, instruindo o paciente acerca de hábitos mais saudáveis de vida e possibilitando uma vivência compartilhada de sua doença no grupo de apoio.

\section{Grupo da terceira idade}

Integrando a atenção à saúde a ações educativas e psicossociais, as equipes do PSF e as estagiárias de psicologia promoveram atividades coletivas de lazer, assistência e convivência entre os idosos do município, como medidas de incentivo ao envelhecimento saudável. As reuniões semanais se estabeleceram como parte da rotina de vida das pessoas, obtendo um nível de participação muito elevado. A reunião dos idosos em torno de uma mesma atividade permitiu e fortaleceu encontros interpessoais, nos quais as pessoas se reconheciam e se identificavam como parte do grupo. Um dos principais objetivos dessa proposta de trabalho com os idosos era o de incentivar o caráter relacional das atividades, contrariando a reclusão e o afastamento social tão característicos nessa fase da vida.

Eram promovidas palestras informativas direcionadas ao público da terceira idade, além de atividades de lazer, tais como tardes de jogos e brincadeiras, bailes, passeios, etc. As atividades envolveram os campos da saúde, educação, lazer e convivência, fazendo sentido para a equipe de saúde a medida em que proporcionaram ganhos nas diversas dimensões humanas, visando fornecer elementos de capacitação que impulsionam o desenvolvimento pessoal dentro do contexto no qual cada indivíduo se encontra.

\section{Grupo de jovens}

O grupo de jovens foi uma atividade promovida no município por um projeto de extensão universitária da UFMG e apoiada pelo PSF. Reunindo adolescentes e adultos jovens de uma das zonas rurais do município, foram realizados encontros quinzenais conduzidos por acadêmicos da UFMG dos cursos de psicologia e medicina, abordando-se temas que permeavam os conflitos da juventude.

As metodologias de caráter fenomenológico e construtivista utilizadas procuraram promover processos dinâmicos de educação e reflexão acerca dos temas já levantados pelo grupo, partindo-se da realidade e dos interesses próprios dos jovens. O impacto positivo dessa atividade foi sendo observado ao longo dos encontros, quando o grupo foi crescendo, se organizando e se definindo em termos de mobilizações coletivas e projetos futuros. A integração entre os jovens foi tal que permitiu inclusive a efetivação de um projeto de geração de renda na forma de uma cooperativa de bijuterias, organizada e administrada por eles mesmos.

O PSF marcou sua participação em atividades relacionadas à saúde de um modo geral, norteadas pelo caráter pedagógico, preventivo e de promoção da saúde. Além disso, oferecendo seus conhecimentos a respeito da comunidade, acompanhando e apoiando o trabalho dos acadêmicos junto aos jovens, o PSF ampliou sua participação nesse projeto para além dos temas pontuais de saúde, na medida em que entendiam a importância de abordagens intersetoriais na promoção de mudanças nas condições de vida das populações.

O incentivo à auto-organização e à autonomia fortaleceu e capacitou o grupo a se desenvolver e a se responsabilizar pelo seu próprio processo de crescimento, individual e coletivo. Sob a perspectiva da qualidade de vida, considerase o sujeito como ativo na descoberta e no desenvolvimento de suas potencialidades, devendo ser capaz de responder às exigências do meio externo a partir de seus próprios recursos, individualmente ou por meio da organização coletiva. As propostas de intervenção partiam do princípio de que subsidiar a capacitação dos sujeitos em direção ao seu desenvolvimento pessoal teria um efeito mais positivo e duradouro do que fornecer a eles os recursos e benefícios pontuais e finitos. Supõe-se que as atividades que procuraram 
estimular as potencialidades individuais de cada sujeito e a organização grupal tem grandes chances de renderem bons frutos a longo prazo. Avalia-se que esse projeto pôde gerar um impacto na reorientação da perspectiva de vida dos adolescentes, a exemplo da experiência com a cooperativa de bijuterias, que pouco a pouco se tornam agentes de um processo de transformação social do lugar onde vivem.

\section{Projeto de Educação em Saúde}

Ampliando o leque de atividades do PSF, um projeto de intervenção de Educação em Saúde em uma das escolas de ensino fundamental e supletivo do município foi efetivado com o objetivo de envolver cerca dos 81 alunos no trabalho voltado para a melhoria da saúde e das condições de vida da comunidade. Na primeira fase do projeto, a participação do PSF consistiu em delimitar, junto com cerca de oito professores da escola, os conteúdos a serem incluídos no programa e habilitá-los a atuarem no processo pedagógico em benefício da saúde. O suporte didático e metodológico desse trabalho ficou a cargo das acadêmicas de psicologia. Dessa maneira, reunindo-se professores, estagiárias e uma das enfermeiras do PSF, o primeiro conteúdo trabalhado foi relativo à alimentação. O tema gerou uma movimentação por parte de toda a escola, culminando em uma gincana que envolveu alunos e professores em atividades ao mesmo tempo lúdicas e educativas e uma feira de saúde, na qual toda a comunidade esteve reunida dentro do ambiente escolar. Dessa forma, a estratégia de promoção da saúde atingiu a população local por uma outra via que não a da assistência à saúde: a escola.

Em uma segunda fase do projeto, que teria início logo após a feira de saúde, deparou-se com a resistência por parte dos professores em aderirem novamente à etapa de capacitação. Com uma participação cada vez mais rarefeita dos docentes, o projeto de educação em saúde foi interrompido. Apesar de seu fim prematuro, demonstrou-se que é possível mobilizar a comunidade a participar ativamente de seu desenvolvimento. A educação em saúde, como um dos pilares da concepção de promoção da saúde, busca estimular um senso de responsabilidade e autonomia do sujeito para com sua saúde, através de informações acessíveis e compreensíveis acerca dos fatores condicionantes e determinantes da saúde (Brasil, Programa de Educação em Saúde, s.d.).

\section{Atendimentos psicológicos}

Respondendo às demandas da população por atendimentos em psicologia, incorporou-se às atividades do PSF um serviço que seguiu um modelo de acolhimento inicial, no qual as queixas da área de saúde mental eram ouvidas pelas acadêmicas de psicologia e, quando necessário, encaminhadas para as alternativas mais adequadas dentro das possibilidades do sistema local. Esse processo inicial de acolhimento e triagem permitiu uma melhor organização da demanda, reduzindo o tempo de espera por atendimentos psicológicos, encaminhando os casos pertinentes e estabelecendo uma ordem de prioridade dos atendimentos.

Através da triagem, foi possível reunir grupos terapêuticos breves no modelo de oficinas de dinâmica de grupo, a partir de demandas que se aproximavam, como forma de promover um espaço de apoio psicológico e acolhedor das vivências individuais dentro de um espaço coletivo. Diante dos benefícios observados com esse trabalho (mudanças comportamentais, alívio de sintomas, desempenho de novos papéis, criação de redes sociais de apoio, entre outros), ao final dos grupos, o desejo das pessoas era de renovar os contratos e continuar se encontrando. Tal alternativa, dentro do contexto de atendimento público de saúde, apresentou-se como eficiente na medida em que demonstrou uma melhora dos sujeitos, favoreceu atendimentos mais ágeis e ampliou a capacidade do sistema, sem comprometer a qualidade dos serviços. Existe ainda a necessidade de se ampliar o número de vagas para atendimentos individuais subseqüentes, visto que determinados casos não são indicados para abordagens em grupos. Partindo do princípio da integralidade das ações de saúde preconizadas, serviços diferenciados deveriam estar sendo disponibilizados a fim de que se atenda às diversas demandas. Além disso, diante da multidimensionalidade da saúde, garantir a atenção efetiva no nível psicológico é também contribuir para o bem-estar e para a qualidade de vida da população.

\section{Planejamento estratégico com as equipes de saúde}

A atuação da psicologia no PSF não se limitou a intervenções voltadas apenas para a população. Tendo em vista os objetivos de também promover a qualidade de vida no trabalho dos profissionais do PSF e de organizar suas ações, foram abordados os problemas vividos na rotina de trabalho, e implementado um programa de planejamento das atividades. Ao se abordar a vivência de cada pessoa como profissional do PSF, emergiu um número grande de fatores que estaria prejudicando o trabalho das equipes. O convívio diário com a problemática social da comunidade, com a precariedade das condições de trabalho, os baixos salários e os conflitos internos, foram apontados como os principais elementos que comprometiam a qualidade do trabalho em equipe e da assistência à população. Sob a dimensão organizacional, as intervenções se nortearam pelo objetivo de promover o diálogo entre as pessoas e, partindo de um esforço conjunto, melhorar a convivência e elevar a motivação do grupo para o trabalho.

Uma segunda fase dessa intervenção teve a intenção de delinear, junto com as equipes, as ações a serem implementadas futuramente, por meio da organização de projetos de trabalho e da definição de objetivos de longo prazo. As atividades do PSF foram incluídas dentro de um planejamento que atenderia às necessidades da população e que estivesse de acordo com as possibilidades e objetivos do programa. A fim de ampliar os serviços prestados pelo 
PSF, várias propostas surgiram ao longo dessas reuniões, como demandas percebidas pelas equipes de saúde. Durante o processo, percebeu-se uma melhora na comunicação e interação entre os profissionais. Os encontros semanais se configuraram como momento propício para a organização e avaliação processual do programa, contribuindo não só para a elevação da qualidade dos serviços prestados, mas para a melhoria das condições de trabalho desses profissionais. As expectativas futuras são de que, depois de alcançarem um bom nível de organização interna por meio da execução do planejamento, as equipes possam aprimorar sua relação com os ambientes externos ao PSF. Acredita-se que a melhoria na prestação de serviços passa não só pela organização das ações do programa, mas pela articulação intersetorial entre as diversas instâncias envolvidas no processo de promoção da saúde e bem-estar social.

\section{Conclusões}

As equipes de saúde do PSF, referenciadas na estratégia definida pelo atual modelo de organização da saúde pública do Brasil, têm realizado suas atividades visando cumprir com o compromisso de promover a saúde e elevar a qualidade de vida da população que atende. Na medida em que se entende o conceito de qualidade de vida por um viés multidimensional, considerando o caráter biopsicossocial da natureza humana, um programa de assistência à saúde não limita seu trabalho a intervenções de nível epidemiológico e sanitário. Elementos de caráter pessoal, social e econômico, entre outros, devem ser incluídos no planejamento e definição das estratégias.

No município em que se deu a presente experiência, as ações descritas pretendiam atingir as condições físicas, psicológicas e sociais da população como forma de trabalhar efetivamente na elevação de sua qualidade de vida. A integração da equipe de saúde com outras instâncias sociais, tais como escolas, organizações comunitárias, poder público, etc., possibilitou uma atenção a outras necessidades de vida além das de saúde, como prevê a Constituição Federal de 1988.

Tendo em vista a preocupação de responder de maneira mais adequada às necessidades da população, as intervenções do PSF procuraram se basear nas características particulares das pessoas atendidas. Na prática do inquérito e das visitas domiciliares era possível conhecer a realidade das famílias. Essa aproximação das equipes de saúde com a comunidade foi fundamental quando se percebeu que quanto mais a intervenção fosse congruente com a demanda, melhores seriam os resultados. Como princípio preconizado pelo programa, a contextualização das ações é um elemento inscrito no trabalho do PSF por meio de uma postura de observação, sensibilidade e flexibilidade dos profissionais envolvidos. O caráter contextual dessas ações se mostra essencial na busca de incentivos à participação e ao controle social, fatores também preconizados pelo novo modelo de atenção. Ao se identificar com a proposta, a população se coloca mais disposta a participar e a apoiar as ações que dizem respeito a problemáticas pessoais, o que favorece a mobilização e o engajamento de todos. Tendo em vista que o processo de elevação da qualidade de vida é resultado de uma disponibilidade pessoal e subjetiva de cada indivíduo na apropriação de benefícios externos, a implicação popular é um fator essencial. O princípio da participação popular previsto pelas políticas de promoção da saúde e da qualidade de vida objetiva implicar cada sujeito e a comunidade em geral com seu próprio processo de desenvolvimento e fortalecer os vínculos de compromisso e co-responsabilidade entre comunidade e equipes de saúde. A busca de uma melhor qualidade de vida suscita a participação efetiva e concreta da população, assegurada pelo diálogo, troca permanente de idéias, conhecimentos e informações. Além disso, saúde como direito de cidadania garantido pela Constituição Federal prevê o controle social como forma de intervir no planejamento e fiscalização das ações de saúde, sendo necessário, portanto, que seja ativo e efetivo. Acredita-se que apenas quando se considera os interesses e as necessidades da população será possível a construção de um sistema de saúde pública que trabalhe efetivamente para a elevação da qualidade de vida da comunidade.

A exemplo do que ocorre no referido município, a presença da psicologia no PSF se mostra como uma proposta que tem muito a contribuir. A abordagem dos grupos, a realização de reuniões com os diversos setores da comunidade e o contato com os pacientes durante os atendimentos psicológicos se desenvolveram através de estratégias participativas e de posturas atentas de investigação que pudessem constatar demandas reais. Além disso, com o suporte da psicologia as intervenções foram sendo adequadas no sentido de trabalharem no fortalecimento de habilidades individuais e coletivas de enfrentamento dos problemas e no desenvolvimento de potencialidades. Nos grupos programáticos, o caráter educativo e de sensibilização esteve centrado no objetivo de aprimorar as capacidades de convivência positiva e saudável do sujeito com sua doença, a partir da conscientização dos sujeitos, do incentivo à autonomia e da necessidade de comprometimento de cada um no processo de promoção da saúde pessoal. Acredita-se que à medida que se alcança a implicação de cada sujeito no seu movimento de mudança de hábitos, promovem-se condições de vida saudáveis mais efetivas e duradouras. As intervenções consideraram também as práticas educativas significativas como meios que possibilitariam a transformação da realidade em favor da melhoria das condições de saúde e da qualidade de vida. O trabalho da psicologia baseou-se em uma postura mediadora e facilitadora na promoção dos meios que permitiriam à população desenvolver seu potencial em benefício de seu bem-estar.

No contexto da saúde pública, a abordagem da doença em grupos mostrou-se como uma alternativa interessante. Os benefícios dessas propostas foram constatados não só pelo alcance de um grande número de pessoas, mas principalmente por promover no espaço grupal a ampliação de perspectivas individuais que favorecessem a saúde e uma rede de apoio social mútuo. Baseando-se na troca de experiências entre os 
indivíduos, as interações interpessoais favoreceram a apresentação de novas possibilidades, o compartilhamento de vivências e o encontro de alternativas pessoais mais saudáveis.

Entendendo-se também que a satisfação da população com os serviços de saúde incentiva seu comprometimento com as atividades propostas, sendo essa uma condição primordial para que o processo de elevação da qualidade de vida realmente ocorra, as intervenções da psicologia junto às equipes do PSF no trabalho de planejamento estratégico adotaram a busca pela eficiência e pela qualidade do atendimento como meta. A organização do trabalho não teve um fim em si mesmo, mas visou o aprimoramento da oferta dos serviços de saúde, beneficiando a população. A ênfase na melhoria da atenção primária à saúde inclui ainda a tentativa de integração desta com os outros níveis de atenção, visando garantir a qualidade dos serviços em todos os níveis. Nesse movimento, o PSF reivindica também a melhoria do sistema de referência municipal disponível no âmbito da recuperação da saúde. Sendo um direito da população usufruir tanto dos serviços mais básicos quanto de atendimentos específicos e complementares, a reorganização do modelo de assistência à saúde supõe sistemas de referência e contra-referência funcionais e de qualidade, garantindo a integralidade dos atendimentos.

Observa-se que as estratégias de trabalho do PSF, em geral, têm esbarrado nas falhas desse sistema de referência e contra-referência, comprometendo a continuidade da atenção. Apesar dos empecilhos, o programa continua caminhando no sentido de desenvolver ações no âmbito da atenção básica, através da prevenção e da intervenção sobre os fatores de riscos, visando melhores condições de vida e de saúde. A participação da psicologia nesse contexto tem sido relevante na medida em que desenvolve um trabalho integrado ao programa, disponível a promover ações de benefício à saúde e o bem-estar da comunidade, além de melhorias na qualidade dos serviços prestados à população.

\section{Referências}

Allardt, E. (1973). A welfare model for selecting social indicators of national development. Policy Sciences, 4, 64-74.

Brasil, Ministério da Saúde. (1996). Norma Operacional Básica do Sistema Único de Saúde (NOB-SUS 11/96). Brasília: Autor.

Brasil, Ministério da Saúde. (1997). DATASUS, registros administrativos. Disponível em: http://www.datasus.gov.br/. Acesso em agosto de 2001.

Brasil, Ministério da Saúde. (s. d.). Programa de Educação em Saúde. Disponível em: http://www.saude.gov.br/programas/pes/principal.htm. Acesso em agosto de 2001.

Brasil, Ministério da Saúde. (s. d.). Programa de Saúde da Família. Disponível em: http://www.saude.gov.br/psf/programa/index.asp. Acesso em agosto de 2001.

Bronfenbrenner, U. (1996). A ecologia do desenvolvimento humano: experimentos naturais e planejados. Porto Alegre: Artes Médicas (original publicado em 1979).

Conferência Internacional sobre a Promoção da Saúde. (1986). Carta de Ottawa. Ottawa: Autor.

Corrêa, A. L. (2001). Qualidade de vida urbana na Amazônia: os casos de Marapanim e Vila dos Cabanos. Belém: Unama.

Instituto Brasileiro de Geografia e Estatística. (1997). Malha municipal digital do Brasil. Disponível em: http://www.ibge.net/cidadesat/default.php. Acesso em agosto de 2001.

Rudio, F. V. (1998). Diálogo maiêutico e psicoterapia existencial. São José dos Campos: Novos Horizontes.

Rueda, S. (1997). Habitabilidad y calidad de vida: aproximación al concepto de calidad de vida. Disponível em: http://habitat.aq.upm.es/ (Biblioteca ciudades para un futuro más sostenible).

Selltiz, C., Jahoda, M., Deutsch, M., \& Cook, S. W. (1965). Métodos de pesquisa nas relações sociais. São Paulo: Herder.

Sliwiany, R. M. (1997). Sociometria: como avaliar a qualidade de vida. Petrópolis: Vozes.

Wilheim, J. (1978). O substantivo e o adjetivo. São Paulo: Perspectiva.

Nota

1. Atividade acadêmica na qual estudantes dos cursos de graduação em Medicina, Odontologia, Enfermagem, Engenharia Civil, Farmácia e Psicologia da UFMG atuam como estagiários em diversos municípios do interior de Minas Gerais, em regime de internato por um período de 03 meses.

Rafaela Assis de Souza é graduanda em Psicologia da Universidade Federal de Minas Gerais. Alysson Massote Carvalho, doutor em Psicologia Experimental pela Universidade de São Paulo, é professor adjunto no departamento de Psicologia da Faculdade de Filosofia e Ciências Humanas da Universidade Federal de Minas Gerais. Endereço para correspondência: Rua Engenheiro Vicente Assunção, 77 - Bairro Itapoã; Belo Horizonte, MG - CEP 31710-090. Tel.: (31) 3499-4065. Fax: (31) 3499-4066/4068. E-mail: alysson@reitoria.ufmg.br 